\title{
Experimental Study on Influence of Fly Ash Content on Splitting Strength of High-titanium Blast Furnace Slag No-sand Concrete CHEN Wei ${ }^{1,}$ a, LIAO Fei ${ }^{1,4}$, XU Xiaoqian ${ }^{3}$, ZHONG Song ${ }^{1,2,4, b}$, WANG Wei ${ }^{1}$
}

(1. Utilization of Industrial Solid Waste, Panzhihua University,Panzhihua 617000, Sichuan, China; 2. CBMI Construction Co., Ltd, Beijng 100176, China;

\section{China Southwest Geotechnical Investigation \& Design Institute Company Yunnan} Branch,Kunming 650224, Yunnan, China;

\section{School of Architecture and Civil Engineering, Xihua University,Chengdu 610039, Sichuan, China ) a2233914335@qq.com, b463203007@qq.com}

Keywords: High-titanium blast furnace slag; No-sand concrete; Splitting strength Abstract. In order to study the effect of fly ash content on the splitting strength of high-titanium blast furnace slag no-sand concrete, in this experimental study, $0 \%, 5 \%, 10 \%, 15 \%, 20 \%, 25 \%$ and $30 \%$ of the cement content are replaced by fly ash. Water-cement ratio is 0.5 , and the cement-aggregate ratio is 1:5.0. By experiment, the splitting strength of the high-titanium blast furnace slag no-sand concrete in $28 \mathrm{~d}$ is tested. The test results show that: With the increase of fly ash content, the splitting strength of high-titanium blast furnace slag no-sand concrete presents the development tendency of decreasing first and then increasing and decreasing again. When the fly ash content is about $20 \%$, the splitting strength of high-titanium blast furnace slag no-sand concrete reaches the biggest value. When the fly ash content exceeds $20 \%$, the splitting strength of high-titanium blast furnace slag no-sand concrete shows the tendency of decreasing.

\section{Introduction}

In Panxi region, the deposition amount of high-titanium blast furnace slag has accumulated to tens of millions of tons. The deposition of a large number of high-titanium blast furnace slag not only causes environmental pollution, but also is a great waste of resources. Using high-titanium blast furnace slag as concrete aggregate is considered to be one of the effective ways of comprehensive utilization of resources, which not only solves the high-titanium blast furnace slag's issues of occupying a lot of lands, polluting the environment and so on, but also saves many building materials and reduces the massive exploration of natural sand and stone ${ }^{[1]}$. At present, a series of scientific achievements have been made on researches on high-titanium blast furnace slag, mainly being used in roads, bridges, housing construction and other structures, but domestic and foreign researches on high-titanium blast furnace slag no-sand concrete are basically at the blank stage. How to use high-titanium blast furnace slag high efficiently to prepare high-titanium blast furnace slag no-sand concrete is the current problem needed to solve ${ }^{[2]}$. Therefore, it has great significance to do experimental study on the high titanium blast furnace slag no-sand concrete.

\section{Experimental Raw Materials}

High-titanium blast furnace slag no-sand concrete is called macroprous or porous concrete. It is a kind of concrete materials with skeleton-pore structure which is formed as cement slurry coats high-titanium blast furnace slag gravel. As the pores in the high-titanium blast furnace slag no-sand concrete are big, the thermal conductivity is low and water permeability is high. In irrigation works, no-sand concrete is mainly used to make drainage ditches and drains of the filter drainage. The main difference between high- titanium blast furnace slag no-sand concrete and ordinary concrete is that: High-titanium blast furnace slag no-sand concrete has no-sand aggregate, only mixed with coarse aggregate of high-titanium blast furnace slag. Cement slurry encapsulates the surface of coarse aggregate, taking cementation effect, rather than filling the gap, so the cement content is less than that 
of ordinary concrete, generally $200 \sim 350 \mathrm{~kg} / \mathrm{m}^{3}$. The high-titanium blast furnace slag gravel with the grain diameter between $4.75 \mathrm{~mm}$ and $19 \mathrm{~mm}$ is selected as coarse aggregate, and it is better to use high-titanium blast furnace slag gravel with more uniform grains.

2.1 Cement. Cement is an important composition material of high-titanium blast furnace slag no-sand concrete. In this test, ordinary Portland cement for grade P.O.42.5R produced by Panzhihua Ruifeng Building Materials Company is used. The physical and mechanical properties are shown in Table 1.

Table 1 Ordinary portland cement for grade P.O.42.5R

\begin{tabular}{ccccccccc}
\hline $\begin{array}{c}\text { Fineness } \\
(80 \mu \mathrm{m}\end{array}$ & $\begin{array}{c}\text { Water } \\
\text { requirement } \\
\text { screen }\end{array}$ & $\begin{array}{c}\text { Setting time } \\
/(\mathrm{min})\end{array}$ & $\begin{array}{c}\text { Compressive } \\
\text { strength } \\
/(\mathrm{Mpa})\end{array}$ & $\begin{array}{c}\text { Flexural } \\
\text { strength } \\
/(\mathrm{Mpa})\end{array}$ & Stability \\
\cline { 3 - 6 } $\begin{array}{c}\text { residue on } \\
\text { square hole } \\
\text { sieve }) /(\%)\end{array}$ & $\begin{array}{c}\text { consistency/ard } \\
(\%)\end{array}$ & $\begin{array}{c}\text { Initial } \\
\text { setting }\end{array}$ & $\begin{array}{c}\text { Final } \\
\text { setting }\end{array}$ & $3 \mathrm{~d}$ & $28 \mathrm{~d}$ & $3 \mathrm{~d}$ & $28 \mathrm{~d}$ & (Boiling) \\
\hline$<10$ & 29.6 & 115 & 182 & 29.2 & 51.3 & 6.0 & 8.5 & Qualified \\
\hline
\end{tabular}

2.2 High-titanium Blast Furnace Slag Gravel. High-titanium blast furnace slag no-sand concrete has certain requirements on aggregates' shape, apparent situation, water absorption and grain gradation, etc.. In this test, high titanium blast furnace slag gravel produced by Panzhihua Huanye Company is used. Its shape, apparent situation, water absorption and grain gradation are worse than that of ordinary gravel, which have a certain impact on the preparation of high-titanium blast furnace slag no-sand concrete. The experimental aggregate is the high-titanium blast furnace slag gravel with grain diameter between $4.75 \mathrm{~mm}$ and $19 \mathrm{~mm}$. The basic properties are shown in Table 2, Table 3 and Fig 1.

Table 2 Data table of grain gradation of high-titanium blast furnace slag gravel

\begin{tabular}{ccc}
\hline $\begin{array}{c}\text { Grain } \\
\text { diameter }\end{array}$ & $\begin{array}{c}\text { Separate } \\
\text { calculations } \\
\text { of screen } \\
\text { residue } /(\%)\end{array}$ & $\begin{array}{c}\text { Accumulative } \\
\text { calculations } \\
\text { of screen } \\
\text { residue } \\
/(\%)\end{array}$ \\
\hline $16 \sim 19 \mathrm{~mm}$ & 11.68 & 11.68 \\
$9.5 \sim 16 \mathrm{~mm}$ & 65.98 & 77.66 \\
$4.75 \sim 9.5 \mathrm{~mm}$ & 21.27 & 98.93 \\
$<4.75 \mathrm{~mm}$ & 1.07 & 100.00 \\
\hline
\end{tabular}

Table 3 Physical properties of high-titanium blast furnace slag gravel

\begin{tabular}{cccccc}
\hline $\begin{array}{c}\text { Apparent } \\
\text { density }\end{array}$ & $\begin{array}{c}\text { Bulk } \\
\text { density } \\
/(\mathrm{kg} / \mathrm{m} 3)\end{array}$ & $\begin{array}{c}\text { Moisture } \\
\text { content } \\
/(\mathrm{kg} / \mathrm{m} 3)\end{array}$ & $\begin{array}{c}\text { Saturated } \\
\text { surface-dry } \\
\text { water } \\
\text { absorption } \\
/(\%)\end{array}$ & $\begin{array}{c}\text { Crush } \\
\text { index }\end{array}$ & $\begin{array}{c}\text { Porosity } \\
/ \%)\end{array}$ \\
\hline 2790 & 1650 & 0.66 & 4.52 & 9.5 & 20 \\
\hline
\end{tabular}

2.3 Fly Ash. Experimental fly ash is the GradeIClass F fly ash produced by Comprehensive Industry Branch Company of Panzhihua Steel Group. 


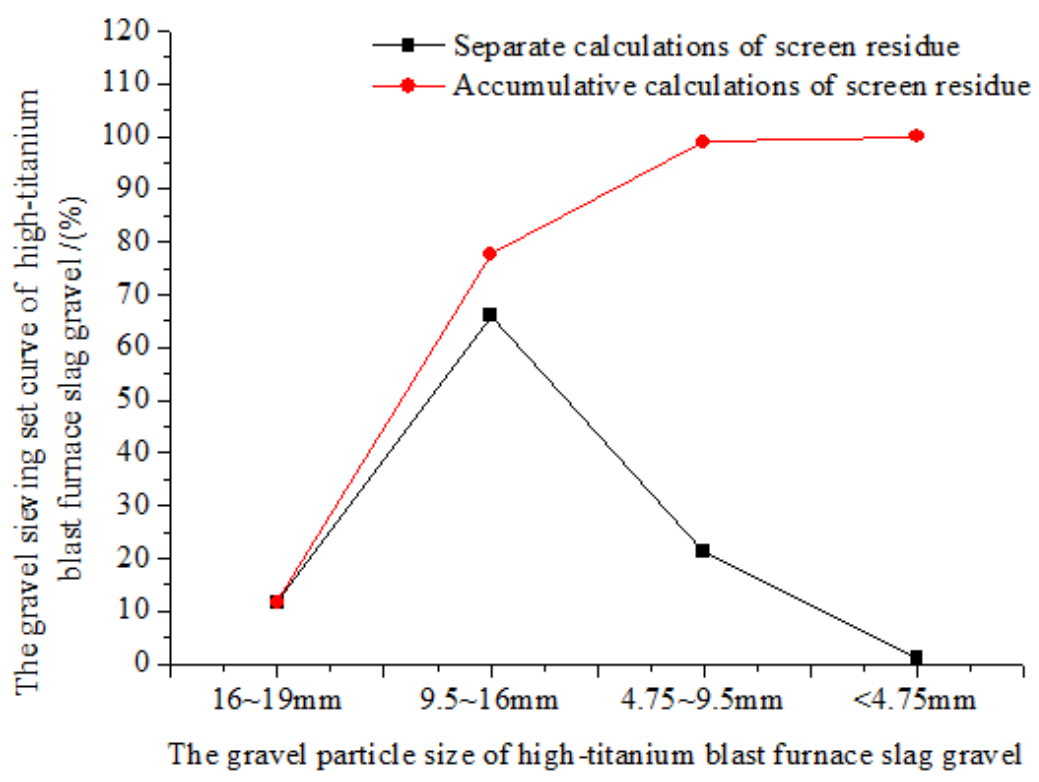

Fig. 1 Screen residue gradation graph of high-titanium blast furnace slag gravel

\section{Experimental Method}

3.1 Mixing Approach. High-titanium blast furnace slag no-sand concrete is not mixed with fine aggregate. In the mixing process of high-titanium blast furnace slag no-sand concrete, it is important to pay special attention to the addition order of materials. Wet the mixing tool first, and calculate the amount of raw materials required for each test according to a fixed mix proportion design ${ }^{[3]}$. Put coarse aggregate of high-titanium blast furnace slag in the concrete agitator and place $20 \%$ of water on the surface of the coarse aggregate. Start the agitator to wet the coarse aggregate. After stirring for 30 s, stop the agitator and mix the cement and the required fly ash. After stirring for another 30 seconds, pour the remaining water, adding water while stirring. Then continue to stir for 90 s and then stop stirring. Finally, put the mixture into a $150 \mathrm{~mm} \times 150 \mathrm{~mm} \times 150 \mathrm{~mm}$ standard test mold.

3.2 Molding Process. In the molding process, statics pressure forming method is used to make high-titanium blast furnace slag no-sand concrete. Statics pressure forming method can make the aggregate of high-titanium blast furnace slag no-sand concrete more fitted and close-grained, while the cement slurry will not sink to clog the lower part of the pore ${ }^{[4]}$. The specific method of the test is that: Put the mixed high-titanium blast furnace slag no-sand concrete into the standard test mode by dividing into two layers. The mixture should be about $10 \mathrm{~mm}$ higher than the edge of test mold. Then, place a $150 \mathrm{~mm} \times 150 \mathrm{~mm} \times 30 \mathrm{~mm}$ press-board above the mixture. The size of the press-board is corresponding to that of the test mold. Apply pressure at the speed of $0.5 \mathrm{KN} / \mathrm{s}$ up to $30 \mathrm{KN}$ with the test press machine, stabilize the pressure for 1 minute and then release pressure. Here, standard test specimens are molded and completed ${ }^{[5]}$.

3.3 Specimens Maintenance Method. Demould test specimens of high-titanium blast furnace slag no-sand concrete after having molded for 24 hours and maintain the test specimens by using the standard maintenance method, that is, test specimens should be maintained in a condition with $95 \%$ relative humidity and temperature of $20^{\circ} \mathrm{C} \pm 2{ }^{\circ} \mathrm{C}$.

3.4 Measurement of Splitting Strength. The splitting strength test of high-titanium blast furnace slag no-sand concrete adopts the splitting-tensile strength test method of cement concrete cubes in Test Methods of Cement and Concrete for Highway Engineering, (JTG E30-2005). In this test, standard cube specimens with the size of $150 \mathrm{~mm} \times 150 \mathrm{~mm} \times 150 \mathrm{~mm}$ are used. Before the test, mark the position line of the splitting surface, put the test specimens on the ball seat, geometric alignment, and place properly the filler strip, making the direction perpendicular to the top of the test specimens to fix test specimens. Control the loading speed of the test press machine and make it load at the speed of 
$0.02 \sim 0.05 \mathrm{MPa} / \mathrm{s}$. The arithmetic average of the test values of three test specimens is the test result, and the test result is accurate to $0.01 \mathrm{MPa}$.

Accumulate the splitting strength of high-titanium blast furnace slag no-sand concrete test specimens by the following formula:

$$
f_{t s}=\frac{2 F}{\pi A}
$$

In the formula:

$f_{t s}$ - unconfined splitting strength of test specimens (MPa);

$\mathrm{F}$ - ultimate load ( N) ;

A - splitting surface area of test specimens $\left(\mathrm{mm}^{2}\right)$, that is the cross sectional area of test specimens.

\section{Experimental Results Analysis}

The fly ash content not only affects the compressive strength of high-titanium blast furnace slag no-sand concrete, but also has certain effect on the splitting strength. In this experimental study, $0 \%$, $5 \%, 10 \%, 15 \%, 20 \%, 25 \%$ and $30 \%$ of the cement content are replaced by fly ash. Among mixture ratio, water-cement ratio is 0.5 , and the cement-aggregate ratio is $1: 5$. PO42.5R ordinary Portland cement is used, and the high-titanium blast furnace slag gravel with grain diameter between 4.75 and $19 \mathrm{~mm}$ is taken as coarse aggregate. By experimental comparison analysis, the effects of different fly ash content on the splitting strength of high-titanium blast furnace slag no-sand concrete are studied. The test results are shown in Table 4.

Table 4 Effects of fly ash content on the splitting strength of high-titanium

blast furnace slag no-sand concrete

\begin{tabular}{ccccccc}
\hline $\begin{array}{c}\text { Gradation } \\
\text { type }\end{array}$ & $\begin{array}{c}\text { Water- } \\
\text { cement } \\
\text { ratio }\end{array}$ & $\begin{array}{c}\text { cement- } \\
\text { aggregate } \\
\text { ratio }\end{array}$ & $\begin{array}{c}\text { Fly ash } \\
\text { content } \\
/(\%)\end{array}$ & $\begin{array}{c}\text { Effective } \\
\text { porosity } \\
/(\%)\end{array}$ & $\begin{array}{c}\text { Total } \\
\text { porosity } \\
/(\%)\end{array}$ & $\begin{array}{c}\text { Splitting } \\
\text { strength in } \\
28 \mathrm{~d} /(\mathrm{MPa})\end{array}$ \\
\hline A & 0.5 & $1: 5$ & 0 & 23.14 & 36.18 & 1.341 \\
B & 0.5 & $1: 5$ & 5 & 21.59 & 35.12 & 1.160 \\
C & 0.5 & $1: 5$ & 10 & 25.42 & 36.09 & 1.216 \\
D & 0.5 & $1: 5$ & 15 & 24.10 & 36.26 & 1.306 \\
E & 0.5 & $1: 5$ & 20 & 19.19 & 34.53 & 1.402 \\
F & 0.5 & $1: 5$ & 25 & 22.69 & 35.48 & 1.127 \\
G & 0.5 & $1: 5$ & 30 & 23.53 & 36.61 & 1.054 \\
\hline
\end{tabular}

It can be seen from Table 4 and Fig. 2 that with the increase of fly ash content, the splitting strength of high-titanium blast furnace slag no-sand concrete presents the development tendency of decreasing first and then increasing and decreasing again. When the fly ash content is $0 \%$, the total porosity is $36.18 \%$ and the splitting strength in $28 \mathrm{~d}$ is $1.341 \mathrm{MPa}$; When the content of fly ash is $20 \%$, the total porosity is $34.53 \%$ and the splitting strength in $28 \mathrm{~d}$ is $1.402 \mathrm{MPa}$; When the fly ash content is $30 \%$, the total porosity is $36.61 \%$ and splitting strength in $28 \mathrm{~d}$ is $1.054 \mathrm{MPa}$. This is because appropriate fly ash content has a certain effect on changing the properties of cement stone and can enhance the splitting strength of high-titanium blast furnace slag no-sand concrete. The results show that: the fly ash content has a certain influence on the splitting strength of high-titanium blast furnace slag no-sand concrete. When the fly ash content is about $20 \%$, the splitting strength value is the biggest. 


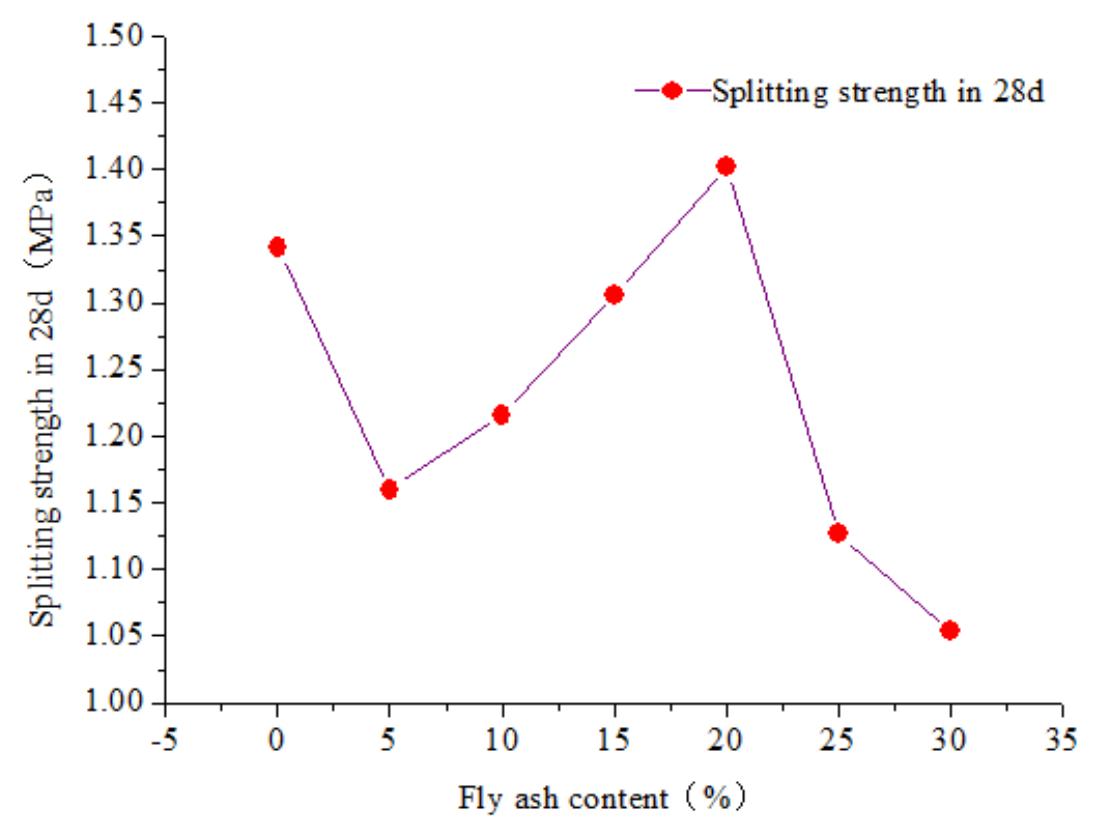

Fig.2 Curve of influence of fly ash on splitting strength of high-titanium

blast furnace slag no-sand concrete

\section{Conclusion}

(1) The splitting strength of high-titanium blast furnace slag no-sand concrete is affected by the fly ash content. With the increase of fly ash content, the splitting strength of high-titanium blast furnace slag no-sand concrete presents the development law of decreasing first and then increasing and decreasing again.

(2) The fly ash content has a certain effect on the splitting strength of high-titanium blast furnace slag no-sand concrete. When the water-cement ratio is 0.5 , the cement-aggregate ratio is $1: 5.0$, and the fly ash content is about $20 \%$, the splitting strength of the high-titanium blast furnace slag no-sand concrete in $28 \mathrm{~d}$ is $1.402 \mathrm{MPa}$, reaching the biggest value. When the fly ash content exceeds $20 \%$, the splitting strength of high-titanium blast furnace slag no-sand concrete shows the tendency of decreasing.

\section{References}

[1] W. Huiqun, Solid Wastes Treatment and Resource, Chemical Industry Press, Beijing, China, 2004 (Chinese).

[2] H. Huanghua, C. Wei, S. Jingkun, and C. Jiayun, "Application of high-titanium and blast furnace slag in concrete materials", New Building Materials, no.11,pp.71-73,2006 (Chinese).

[3] W. Chenwei, “ The Research on No-sand Concrete Drainage Road Base”, [master dissertation], Changsha: Changsha University of Science \& Technology, 2013 (Chinese).

[4] T. Xinming, "No-fines macroprous concrete mixing ratio design, forming and curing", Concrete, no. 10, pp. 136-141, 2010 (Chinese).

[5] Z. Mulian, "Study on Porous Permeable Base", [doctor dissertation], Shanxi: Chang'an University, 2004 (Chinese). 